\title{
Genome-enabled analysis of the utilization of taurine as sole source of carbon or of nitrogen by Rhodobacter sphaeroides 2.4.1
}

Correspondence

Alasdair M. Cook

alasdair.cook@uni-konstanz.de

Received 6 June 2006

Revised 25 July 2006

Accepted 26 July 2006

\author{
Karin Denger, Theo H. M. Smits and Alasdair M. Cook \\ Department of Biology, The University, D-78457 Konstanz, Germany
}

\section{INTRODUCTION}

Taurine (2-aminoethanesulfonate) (Fig. 1a) is 'a phylogenetically ancient compound with a disjunct distribution in the biosphere' (Huxtable, 1992). Absent in plants, it is a major organic solute in mammals $\left[1 \mathrm{~g}(\mathrm{~kg} \text { wet } \mathrm{wt})^{-1}\right]$, which excrete it (largely in urine), and it is found free or derivatized in all vertebrates, many marine creatures, algae and bacteria (e.g. Allen \& Garrett, 1971; Vollrath et al., 1990; Huxtable, 1992; Yin et al., 2000; Abraham et al., 2004). Spiders secrete molar concentrations of $\mathrm{N}$-acetyltaurine on their webs (Vollrath et al., 1990). The widespread supply of extracellular (and intracellular) taurine is presumed to explain the large number of terrestrial and marine bacteria able to utilize the compound as sole source of carbon for aerobic growth, as a source or sink of electrons in respirations, and in fermentations or in photoheterotrophic growth (e.g. Lie et al., 1998; Cook \& Denger, 2002; Denger et al., 2004a; Novak et al., 2004). The compound can also serve as a sole source of sulfur for growth (e.g. Kertesz, 2000), and a range

Abbreviations: Ald, alanine dehydrogenase; Pta, phosphate acetyltransferase; RT, reverse transcription; TDH, taurine dehydrogenase; Tpa, taurine: pyruvate aminotransferase; TRAP, tripartite ATP-independent; Xsc, sulfoacetaldehyde acetyltransferase. of phenomena can be involved when organisms utilize the compound as a sole source of nitrogen; these include deamination without desulfonation, not always concomitant with substrate utilization (Denger et al., 2004b; Styp von Rekowski et al., 2005; Weinitschke et al., 2005), and utilization concomitant with taurine carbon (Denger et al., 2004a). Two general pathways for the dissimilation of taurine have been hypothesized (Cook \& Denger, 2006), one of which has received significant experimental support in Silicibacter pomeroyi DSS-3, especially for the genes encoding an ATP-binding cassette transporter (TauABC), taurine:pyruvate aminotransferase (Tpa) and alanine dehydrogenase (Ald) (analogous to Fig. 1a, bottom left), as well as sulfoacetaldehyde acetyltransferase (Xsc) and phosphate acetyltransferase (Pta) (Gorzynska et al., 2006).

The second hypothesis (Fig. 1a, b, Table 1) was first formulated from data in the partial genome sequence of the facultative phototroph Rhodobacter sphaeroides 2.4.1 (Brüggemann et al., 2004), which now serves as a model organism that represents several genomes or sequences of clusters of taurine-related genes. The hypothesis involves in part a gene cluster now known to be encoded on plasmid B of $R$. sphaeroides 2.4.1 (Fig. 1b). The cluster contains the genes for a putative regulator (tauR) and a tripartite 


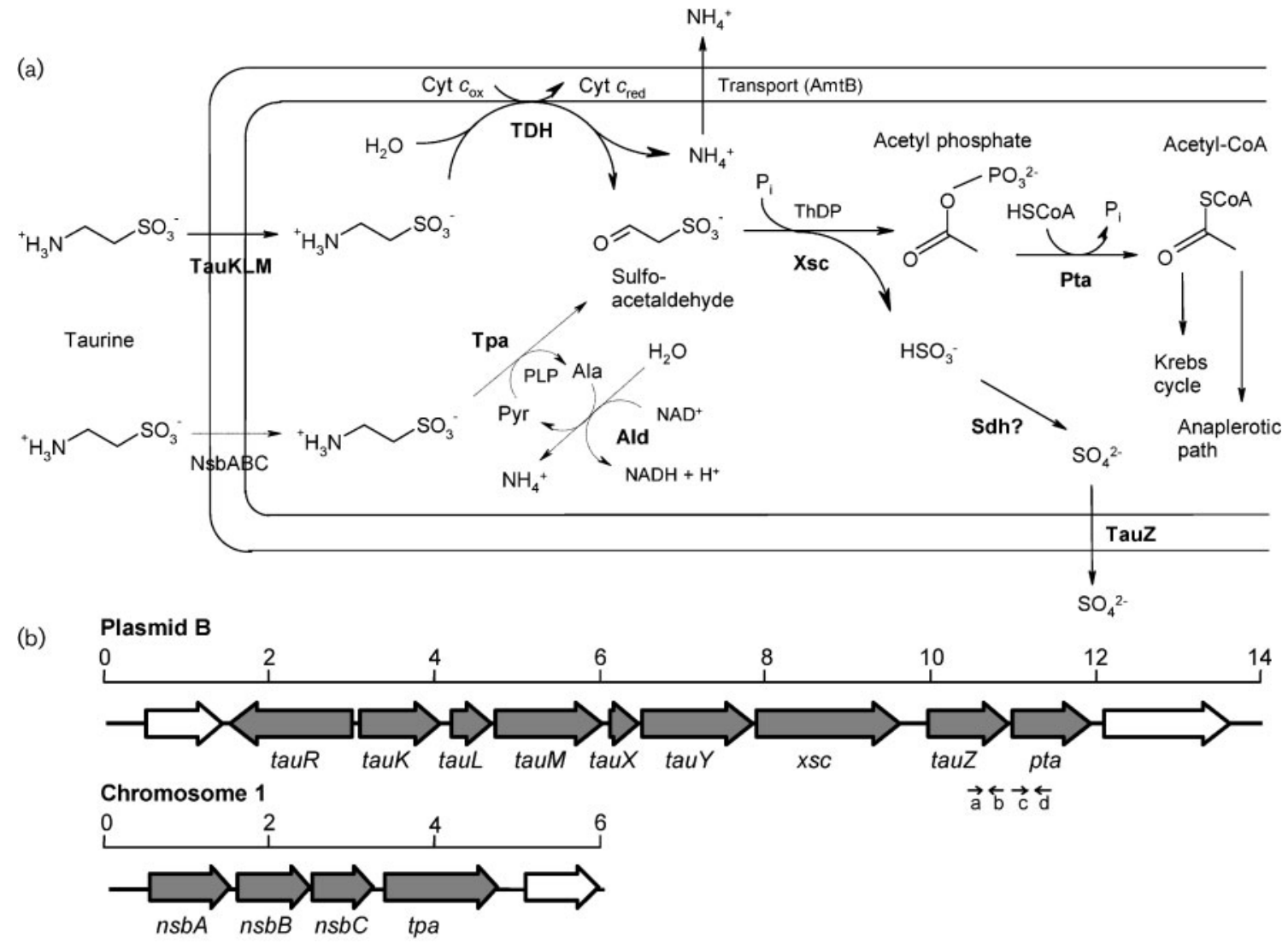

Fig. 1. (a) The pathway of taurine dissimilation in $R$. sphaeroides 2.4.1. The pathway with bold arrows was largely substantiated in this work, whereas the possible alternative route, shown in faint arrows, was shown to play a negligible role. Most abbreviations in the figure are defined in the text and on the title page; Sdh represents sulfite dehydrogenase. (b) Gene clusters relevant to candidate functions (panel a) in taurine dissimilation in $R$. sphaeroides 2.4.1. Small arrows indicate the position of the RT-PCR primers used in Fig. 4: a, RsTauZF; b, RsTauZR; c, RsPtaF; d, RsPtaR.

ATP-independent (TRAP) transport system (tauKLM), for which there is currently no experimental support. The tauXY genes are excellent candidates to encode taurine dehydrogenase (TDH), but this is still unproven (Weinitschke et al., 2006). The xsc gene of $R$. sphaeroides 2.4.1 has a high level $(87 \%)$ of identity to the orthologue encoding a purified Xsc in the phylogenetically related Paracoccus denitrificans NKNIS (Brüggemann et al., 2004). The tau $Z$ gene is presumed to encode a sulfate exporter (Rein et al., 2005). The group of pta genes is well known, but the enzyme is seldom characterized (Lawrence et al., 2006). In addition to the functions ascribed to the gene products from the cluster, an unknown exporter of the ammonium ion released by TDH is needed, and an ammonium/ methylammonium transporter, possibly $\mathrm{AmtB}$, has been proposed (Cook \& Denger, 2006; Gorzynska et al., 2006). The oxidation of sulfite to sulfate is also postulated, but no genes (sor $A B)$ encoding the known sulfite dehydrogenase (Kappler et al., 2000) are present on the genome of $R$. sphaeroides 2.4.1. Whereas the Krebs cycle is known in the organism, the anaplerotic sequence is not (Filatova et al., 2005; Meister et al., 2005). The hypothesis (Fig. 1a) is further complicated by the fact that the genome of $R$. sphaeroides 2.4.1 includes a putative tpa gene (Fig. 1b), whose derived product shares $75 \%$ identity of position with a confirmed Tpa in the partially sequenced genome of Rhodobacter capsulatus SB1003, in which the enzyme is involved in the assimilation of taurine sulfur (Masepohl et al., 2001; see also Laue et al., 2006). The genes located upstream of the putative tpa (Fig. $1 \mathrm{~b}$ ) represent a putative nitrate/sulfonate/bicarbonate $\mathrm{ABC}$ transporter (NsbABC; $\bar{N}$ sbA has $<20 \overline{\%}$ identity with any known TauA). A different isolate of R. sphaeroides, strain Tau3, is reported to express both Xsc and Tpa under conditions of photoheterotrophic utilization of taurine (Novak et al., 2004); the genome of $R$. sphaeroides 2.4.1 potentially encodes, besides the candidate Tpa, a candidate Ald (Table 1), which would allow the regeneration of pyruvate (Fig. 1a) if the Tpa were active. This latter situation is standard in organisms which degrade taurine via Tpa (Laue \& Cook, 2000a, b; Denger et al., 2004a; Gorzynska et al., 2006). The multiple metabolic possibilities involving sequenced genes can be readily studied with a combination of analyses of transcription by reverse-transcription (RT-) PCR and enzymic analyses. 
Table 1. Annotations of portions of the genome of $R$. sphaeroides

\begin{tabular}{|c|c|c|c|}
\hline Rsph no. & Gene & Enzyme & EC (TC) no. \\
\hline RSP_4017* & $\operatorname{tau} R^{\dagger}$ & Transcriptional regulator & \\
\hline RSP_4016* & $\operatorname{tauK} \dagger$ & Substrate binding protein & TC 2.A.56.4.1 \\
\hline RSP_4015* & $\operatorname{tau} L \dagger$ & Small membrane component & TC 2.A.56.4.1 \\
\hline RSP_4014 ${ }^{*}$ & $\operatorname{tau} M \dagger$ & Large membrane component & TC 2.A.56.4.1 \\
\hline RSP_4013* & $\operatorname{tau} X \dagger$ & Small subunit of taurine dehydrogenase & EC 1.4.2.- \\
\hline RSP_4012* & $\operatorname{tau} Y^{\dagger}$ & Large subunit of taurine dehydrogenase & EC 1.4.2.- \\
\hline RSP_4011* & $x s c \dagger$ & Sulfoacetaldehyde acetyltransferase & EC 2.3.3.15 \\
\hline RSP_4010* & $\operatorname{tau} Z \dagger$ & Sulfate exporter & TC 9.B.63.1.1 \\
\hline RSP_4009* & pta†‡ & Phosphate acetyltransferase & EC 2.3.1.8 \\
\hline RSP_0888§ & $a m t B \ddagger$ & Ammonium/methylammonium transport & TC 2.A.49.1.- \\
\hline RSP_0940\$ & $n s b A \ddagger$ & Nitrate/sulfonate/bicarbonate $\mathrm{ABC}$ transporter & TC 3.A.1.-.- \\
\hline RSP_0941§ & $n s b B$ & Nitrate/sulfonate/bicarbonate $\mathrm{ABC}$ transporter & TC 3.A.1.-.- \\
\hline RSP_0942\$ & $n s b C \ddagger$ & Nitrate/sulfonate/bicarbonate $\mathrm{ABC}$ transporter & TC 3.A.1.-.- \\
\hline RSP_0943§ & tpa $\dagger$ & (Taurine aminotransferase) COG0161 & (EC 2.6.1.-) \\
\hline RSP_0723\$ & ald & Alanine dehydrogenase & EC 1.4.1.1 \\
\hline None & & Isocitrate lyase & EC 4.1.3.1 \\
\hline RSP_1980\$ & $g l c B \ddagger$ & (Malate synthase) & $($ EC 2.3.3.9) \\
\hline RSP_1771§ & $m c l 11$ & Malyl-CoA lyase & EC 4.1.3.24 \\
\hline Unknown & & Malyl-CoA hydrolase & EC 3.1.2.- (18?) \\
\hline Unknown & & Sulfite dehydrogenase & EC 1.8.2.1 \\
\hline
\end{tabular}

${ }^{\star}$ Located on plasmid B.

$\dagger$ Annotated by the present authors.

$\ddagger$ Annotated by JGI.

\$Located on chromosome 1.

IlAnnotated by Meister et al. (2005).

We now report that the degradative pathway for taurine as sole source of carbon or nitrogen for growth for $R$. sphaeroides 2.4.1 involves the TRAP transporter and TDH, whereas the tpa orthologue is not relevant.

\section{METHODS}

Bacteria, media and culture conditions. R. sphaeroides $2.4 .1^{\mathrm{T}}$, whose genome has been sequenced, was kindly provided by $\mathrm{S}$. Kaplan, University of Texas, Houston, TX, USA. Cultures of $R$. sphaeroides 2.4 .1 were grown at $30{ }^{\circ} \mathrm{C}$ in the dark in a modification of Sistrom's (Sistrom, 1962) minimal medium. It contained $50 \mathrm{mM}$ potassium phosphate buffer, $\mathrm{pH} 7 \cdot 2,0 \cdot 25 \mathrm{mM} \mathrm{MgSO}_{4}, 9 \mathrm{mM} \mathrm{NaCl}$, $1.2 \mathrm{mM} \mathrm{MgCl}_{2}, 0 \cdot 2 \mathrm{mM} \mathrm{CaCl}_{2}$, trace elements and a vitamin solution (Thurnheer et al., 1986). Different combinations of sources of carbon and nitrogen for growth were used: $10 \mathrm{mM}$ taurine as sole and limiting source of carbon with $2 \mathrm{mM} \mathrm{NH}_{4} \mathrm{Cl}$ [taurine(carbon)-ammonium medium]; $2 \mathrm{mM}$ taurine as nitrogen source (a growth-limiting concentration) with $9 \mathrm{mM}$ succinate [taurine(nitrogen)-succinate medium]; $2 \mathrm{mM} \mathrm{NH}_{4} \mathrm{Cl}$ with $9 \mathrm{mM}$ succinate (succinate-ammonium medium). Purity was checked by streaking on Luria-Bertani agar plates and observing homogeneous, red-coloured colonies.

Precultures $(5 \mathrm{ml})$ were grown in $30 \mathrm{ml}$ screw-cap tubes in a roller. Growth experiments, or cultures for harvesting and preliminary enzyme assays, were done with $50 \mathrm{ml}$ cultures in $300 \mathrm{ml}$ Erlenmeyer flasks on a rotary shaker. Samples were taken in intervals to measure $\mathrm{OD}_{580}$, to quantify protein $\left(\mathrm{OD}_{580} 1 \cong 205 \mathrm{mg}\right.$ protein $\left.\mathrm{l}^{-1}\right)$ and to determine the concentrations of substrate and products. Cells for the preparation of total RNA were grown in the required selective medium and harvested in the mid-exponential phase of growth $\left(\mathrm{OD}_{580} 0 \cdot 3-0 \cdot 7\right)$ by centrifugation at $5000 \mathrm{~g}$, RNA was extracted immediately. Storage of intact cells at $-70^{\circ} \mathrm{C}$ before RNA extraction resulted in complete loss of mRNA.

Preparation of cells grown with taurine as a nitrogen source for RNA extraction or enzyme determination involved a growth phase in taurine(nitrogen)-succinate-salts medium followed by renewed induction by addition of taurine (to $2 \mathrm{mM}$ ) 3-10 h before harvesting. Cells for enzyme purification were grown with taurine as a carbon source at the 1-litre scale in 5-litre Erlenmeyer flasks. Disruption of cells and the preparation of crude extracts, a membrane fraction and a soluble fraction were as described elsewhere (Weinitschke et al., 2006).

Enzyme assays and protein separation. Taurine dehydrogenase (TDH) was measured photometrically with dichlorophenol indophenol as the electron acceptor as described previously (Brüggemann et al., 2004). Taurine: pyruvate aminotransferase (Tpa) was assayed discontinuously as the pyruvate-dependent disappearance of taurine concomitant with the formation of alanine (Brüggemann et al., 2004). Alanine dehydrogenase (Ald) was routinely measured photometrically as the reduction of $\mathrm{NAD}^{+}$(Laue \& Cook, 2000a); S. pomeroyi DSS-3 (Denger et al., 2006) served as a positive control. Sulfoacetaldehyde acetyltransferase (Xsc) was assayed by GC as the ThDP- and phosphate-dependent release of acetate after acidification to hydrolyse the acetyl phosphate formed, or assayed as the formation of sulfite (Ruff et al., 2003). Phosphate acetyltransferase (Pta) was assayed photometrically as the HS-CoA-dependent formation of acetyl-CoA (Bergmeyer et al., 1983). Sulfite dehydrogenase 
was assayed with potassium ferricyanide or beef cytochrome $c$ (Reichenbecher et al., 1999) as the electron acceptor, and Sinorhizobium meliloti Rm1021 (Brüggemann et al., 2004) and Delftia acidivorans NAT (Mayer et al., 2006) were used as positive controls. Other putative electron acceptors, $\mathrm{O}_{2}, \mathrm{NAD}(\mathrm{P}), \mathrm{FAD}$ and nitrate, were tested, as was the possibility of an AMP- or ADPdependent oxidation with ferricyanide or cytochrome $c$ (Hagen \& Nelson, 1997). Isocitrate lyase and malate synthase were assayed as described by Dixon \& Kornberg (1959), and D. acidovorans NAT (Mayer et al., 2006) served as positive control. Malyl-CoA lyase was assayed as described elsewhere (Meister et al., 2005). Anionexchange and hydrophobic interaction chromatography were done with soluble fractions free of nucleic acids as described elsewhere (Ruff et al., 2003; Rein et al., 2005).

Analytical methods. Growth was followed as turbidity $\left(\mathrm{OD}_{580}\right)$ and quantified as protein in a Lowry-type reaction (Cook \& Hütter, 1981). Taurine and alanine were derivatized with dinitrofluorobenzene and subjected to separation by HPLC (Denger et al., 1997). Sulfite was quantified as the fuchsin derivative as described elsewhere (Denger et al., 2001). Sulfate was determined turbidimetrically as a suspension of $\mathrm{BaSO}_{4}$ (Sörbo, 1987). Ammonium ion was assayed colorimetrically by the Berthelot reaction (Gesellschaft Deutscher Chemiker, 1996). Protein in extracts was assayed by protein-dye binding (Bradford, 1976). Denatured proteins were separated in $12 \%$ SDS-PAGE gels and stained with Coomassie Brilliant Blue R250 (Laemmli, 1970).

Molecular methods. Oligonucleotides were synthesized by Microsynth (Balgach, Switzerland). Taq DNA polymerase and MMuLV reverse transcriptase were from MBI Fermentas and they were used as specified by the supplier. Chromosomal DNA was isolated from bacteria as described by Desomer et al. (1991). Total RNA was isolated using the EZNA bacterial RNA kit (Peqlab
Biotechnologie), and contaminant DNA was removed with RNasefree DNase (Qiagen). The RNA was tested for residual DNA before reverse transcription (RT) by PCR using the primer set RsXscFRsXscR. The reverse PCR primers listed in Table 2 were used for RT-PCR reactions. Subsequent PCR reactions were done as described previously (Innis et al., 1990) using chromosomal DNA of R. sphaeroides 2.4.1 as a positive control. PCR products were visualized on $1 \%$ or $1.5 \%$ agarose gels according to standard methods (Sambrook et al., 1989). The GeneRuler DNA ladder mix (MBI Fermentas) was used as molecular marker.

Software for DNA analyses. Sequence analysis of the R. sphaeroides 2.4.1 genome (accession nos CP000143 to CP000147 and DQ232586 to DQ232587) were done using the BLAST algorithm (Altschul et al., 1997) at NCBI. The Lasergene package (DNAStar) was used for routine DNA analyses in silico. Primers for RT and PCR were designed using the program Amplify (version 1.2).

\section{RESULTS}

\section{Taurine as a carbon source for aerobic growth of $R$. sphaeroides 2.4.1}

R. sphaeroides 2.4 .1 grew in $11 \mathrm{mM}$ taurine(carbon)ammonium medium with a specific growth rate $(\mu)$ of $0 \cdot 13 \mathrm{~h}^{-1}$ (Fig. 2a). The utilization of taurine and the excretion of both ammonium and sulfate ions were concomitant with growth (Fig. 2b). The yield of sulfate at the end of growth was $11 \mathrm{mM}$. No sulfite was detected. A net increase of about $9 \mathrm{mM}$ ammonium ion was found in the medium at the end of growth, and we calculated there to be about $2 \mathrm{mM}$ combined nitrogen in cell material in the

Table 2. Primers used in this study

\begin{tabular}{|c|c|c|c|}
\hline Target gene & Primer name & Sequence $\left(5-3^{\prime}\right)$ & Reference \\
\hline \multirow[t]{2}{*}{$x s c$} & RsXscF & GAACATGCGTTCGGGATCAT & This study \\
\hline & RsXscR & GCCCTGCCCGATGGTCTTGTT & \\
\hline \multirow[t]{2}{*}{$\operatorname{tau} X Y$} & RsTauXF & ACCCGCGGCGTGAGCCAGTGGAC & This study \\
\hline & RsTauYR & CGATCACCGCCACATCCACAT & \\
\hline \multirow[t]{2}{*}{$\operatorname{tauK}$} & RsTauKF & ATGATCGAGAAGACGGTCGAGGAT & This study \\
\hline & RsTauKR & AGCGCAGCTCGGTGACATATT & \\
\hline \multirow[t]{2}{*}{$\operatorname{tauL}$} & RsTauLF & CTGTTCTGGATCGGCTTCAACCT & This study \\
\hline & RsTauLR & CTCGTCCTCGGCCAGTTCCATCA & \\
\hline \multirow[t]{2}{*}{$\operatorname{tau} M$} & RsTauMF & CCATGGTCTATCTGGGCGACAA & This study \\
\hline & RsTauMR & CGAGACCGACTGGAAGGGACCGT & \\
\hline \multirow[t]{2}{*}{ tpa } & RsTpaF & GAACTTCGGCGTGAAACCCGATT & This study \\
\hline & RsTpaR & CGGCCCCGCAGAACAGACCCT & \\
\hline \multirow[t]{2}{*}{$\operatorname{tau} Z$} & RsTauZF & GCGAGACGGCGACGCTCGTCAA & This study \\
\hline & RsTauZR & AGACGCCGAGGAAGATCGTTTC & \\
\hline \multirow[t]{2}{*}{ pta } & RsPtaF & GGCCCGCGCCCACCCGCGCCATA & This study \\
\hline & RsPtaR & CAGGCGAGCATGAGAAAGAAGCTC & \\
\hline \multirow[t]{2}{*}{$g l c B$} & RsMSF & GCGCTATGCGCTGAACGCGGCCAA & This study \\
\hline & RsMSR & CAGGCCCCGCGTGGCCCGCAAAT & \\
\hline \multirow[t]{2}{*}{$a m t B$} & RsAmtBF & TCGTGACGCCGGTGATGGACAA & This study \\
\hline & RsAmtBR & TCTGGAAGCAGATGAACAGATA & \\
\hline \multirow[t]{2}{*}{ 16S-rRNA } & $16 \mathrm{~S}-27 \mathrm{~F}$ & CAGAGTTTGATCCTGGCTCAG & Weisburg et al. (1991) \\
\hline & $16 \mathrm{~S}-533 \mathrm{R}$ & TTACCGCGGCTGCTGGCAC & \\
\hline
\end{tabular}


(a)
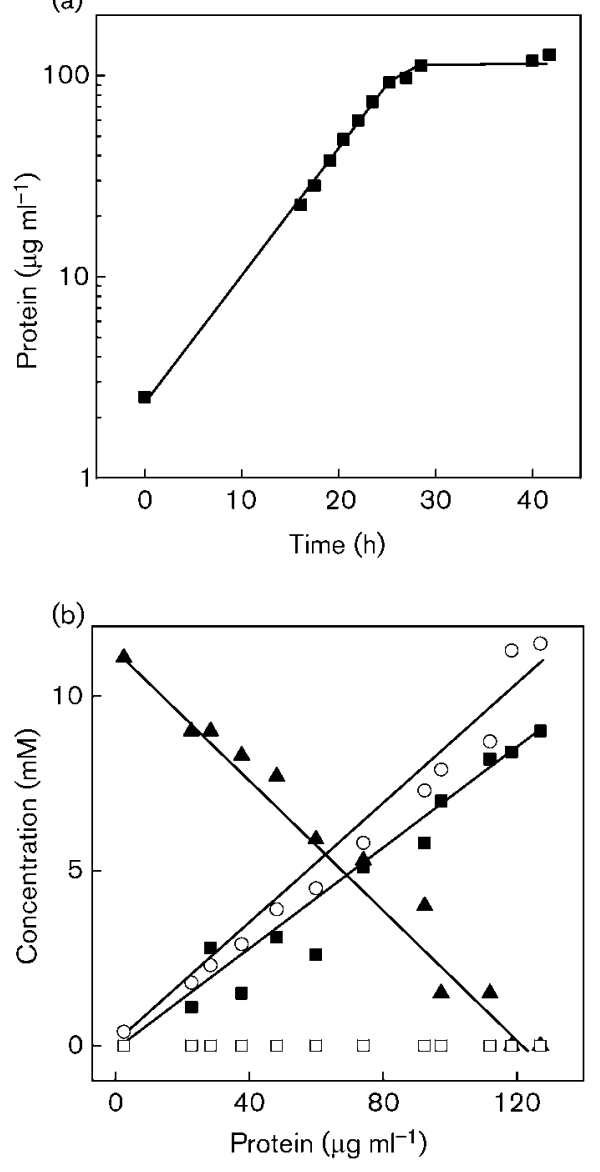

Fig. 2. (a) Growth of $R$. sphaeroides 2.4.1 in taurine(carbon)ammonium medium. (b) Concentrations of substrate and products as a function of the protein concentration: $\boldsymbol{\Delta}$, taurine; ammonium ion; $\bigcirc$, sulfate ion; $\square$, sulfite ion.

medium. The molar growth yield, $6 \mathrm{~g}$ protein $(\mathrm{mol} \mathrm{C})^{-1}$, represented quantitative utilization of the carbon source (Cook, 1987). The data were interpreted to represent a complete mass balance for the carbon, nitrogen and sulfur moieties in taurine.

\section{Taurine as a sole source of nitrogen for $\boldsymbol{R}$. sphaeroides 2.4.1}

R. sphaeroides 2.4 .1 grew biphasically in $2 \mathrm{mM}$ taurine(nitrogen)-succinate medium (Fig. 3a). There was no growth in the absence of combined nitrogen. Taurine was rapidly metabolized, and it disappeared before $25 \%$ of the total growth occurred (Fig. 3b). Over the same period, $2 \mathrm{mM}$ sulfate was formed, so there was mass balance for sulfur; no sulfite was detected (Fig. 3b). Taurine nitrogen was released as the ammonium ion, and the organism then grew with this ammonium; growth was then concomitant with ammonium utilization (Fig. 3b). The overall molar growth yield was 70 g protein (mol taurine- $\mathrm{N})^{-1}$. The same growth yield [about $70 \mathrm{~g}$ protein $(\mathrm{mol} \mathrm{N})^{-1}$ ] was observed in
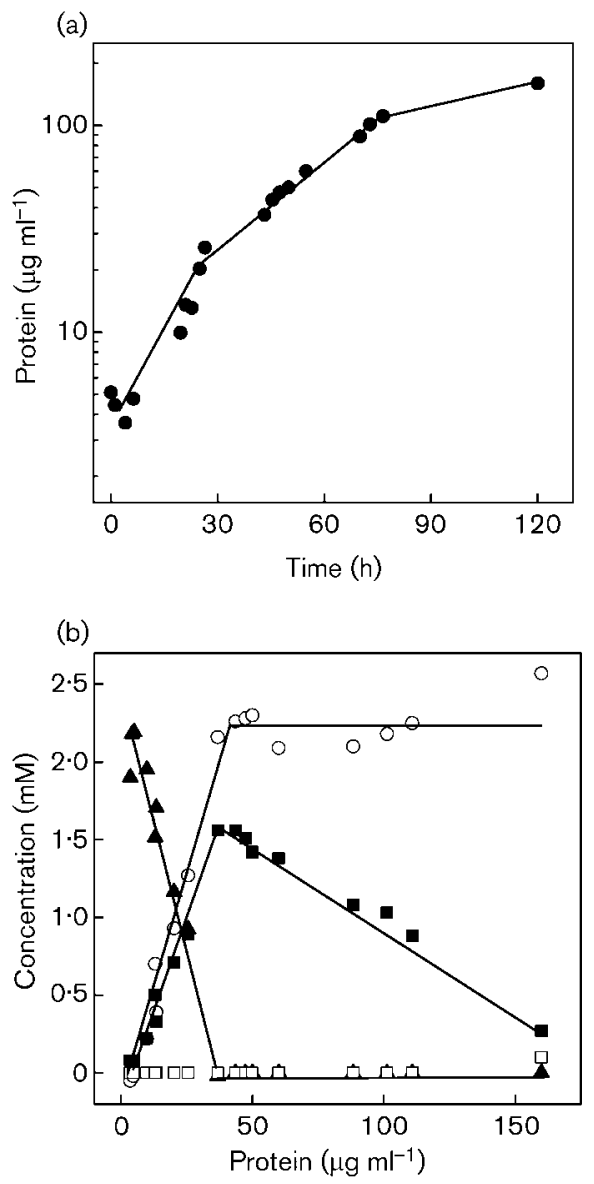

Fig. 3. (a) Growth of $R$. sphaeroides 2.4 .1 in taurine(nitrogen)succinate medium. (b) Concentrations of nitrogen substrate and products as a function of the protein concentration: $\boldsymbol{\Delta}$, taurine; $\mathbf{\square}$, ammonium ion; $\bigcirc$, sulfate ion; $\square$, sulfite ion.

succinate-ammonium medium (not shown), which indicated quantitative assimilation of nitrogen into cell material (e.g. Cook, 1987). The specific growth rate in the presence of taurine was $0.08 \mathrm{~h}^{-1}$; a lower growth rate (maximally $0.03 \mathrm{~h}^{-1}$ ) was observed when the excreted ammonium ion was the sole source of nitrogen (Fig. 3).

\section{Enyzme activities and gene transcription}

The first interactions of cell and substrate in a degradative pathway are the vectorial steps in transport across the cell membrane. Taurine uptake is postulated to be catalysed by an inducible TRAP transporter, TauKLM (Brüggemann et al., 2004). No transcript of any of the corresponding genes was detected in succinate-ammonium-grown cells (Table 3). An amplicon of each of these genes, but especially of tauL and tauM, was obtained from taurine(carbon)ammonium-grown cells (Table 3). Amplicons of tauK, tauL and tauM could also be detected in taurine(nitrogen)succinate-grown cells (Table 3). This is the first direct evidence to show that the tauKLM genes are inducibly 
Table 3. Specific activities of enzymes and transcription of genes under different conditions of growth of $R$. sphaeroides 2.4 .1

Gaps in the table indicate that there is no assay available (e.g. transport) or not applicable (e.g. no gene to express). ND, Not determined; bdl, below detection limit. The limits of detection for TDH, Sor and Ald were 0.02 mkat $(\mathrm{kg} \text { protein })^{-1}$; for Xsc $0 \cdot 3 \mathrm{mkat}(\mathrm{kg} \text { protein })^{-1}$, and for Pta, Icl and malyl-CoA lyase, $0 \cdot 1$ mkat (kg protein $)^{-1}$.

\begin{tabular}{|c|c|c|c|c|c|c|}
\hline Enzyme/transporter & \multicolumn{2}{|c|}{ Succinate $/ \mathrm{NH}_{4}^{+}$} & \multicolumn{2}{|c|}{ Taurine-(C)/ $\mathrm{NH}_{4}^{+}$} & \multicolumn{2}{|c|}{ Taurine-(N)/succinate } \\
\hline TauL & & - & & + & & + \\
\hline TauM & & - & & + & & + \\
\hline Taurine dehydrogenase (TDH, tauXY) & bdl & - & $1 \cdot 0$ & ++ & $0 \cdot 6$ & ++ \\
\hline Sulfoacetaldehyde acetyltransferase (Xsc) & bdl & - & $4 \cdot 2$ & ++ & $3 \cdot 3$ & ++ \\
\hline TauZ & & - & & ++ & & $\mathrm{ND}$ \\
\hline Phosphate acetyltransferase (Pta) & bdl & - & $6 \cdot 0$ & + & $0 \cdot 4$ & ND \\
\hline Sulfite dehydrogenase (Sor) & bdl & & bdl & & bdl & \\
\hline Isocitrate lyase (Icl) & bdl & & bdl & & bdl & \\
\hline
\end{tabular}

${ }^{\star}$ Enz, enzyme activity in mkat $(\mathrm{kg} \text { protein })^{-1}$.

$\dagger$ RNA, RNA transcript, the intensity of amplicons is scored as: - , absent; tr, trace; + , weak band; ++ , strong band (see Fig. 4).

transcribed, and that their gene products are presumably relevant to taurine metabolism.

The activities of several enzymes were assayed in extracts of cells grown with either taurine or succinate as the sole source of carbon. TDH, Xsc and Pta were found in taurine(carbon)-ammonium-grown cells (Table 3) but not in succinate-ammonium-grown cells, so these enzymes were considered to be inducible. Inducible transcription of xsc and pta was detected in these cells (Table 3); inducible synthesis of $\mathrm{TDH}, \mathrm{Xsc}$ and Pta, with the corresponding transcripts, was observed in taurine(nitrogen)-succinategrown cells (Table 3). As in previous work (Brüggemann et al., 2004; Weinitschke et al., 2006), TDH was found to be associated with the particulate fraction of cell extracts, whereas Xsc and Pta were found in the soluble fraction. A transcript from the $\operatorname{tau} X Y$ genes was detected in taurine(carbon)-ammonium-grown cells and in the taurine(nitrogen)-succinate-grown cells, but not in succinateammonium-grown cells (Table 3 ); the amplicon overlapped the tauX and tauY genes, so the signal indicates that these genes are co-transcribed. These data were considered to be further support for the postulate that tauXY encodes TDH (Brüggemann et al., 2004; Weinitschke et al., 2006).

Transamination of taurine was detected, but activity was higher in extracts of succinate-ammonium-grown cells than in extracts of taurine(carbon)-ammonium-grown or taurine(nitrogen)-succinate-grown cells (Table 3). Correspondingly, the transcript from the putative tpa gene was detected in cells from all cultures (Table 3). Further, no Ald activity was detected in extracts of cells grown in the presence of taurine (Table 2), so negligible amounts of pyruvate could be regenerated from alanine. It was concluded that the putative Tpa and Ald made a negligible contribution to taurine dissimilation.

Sulfite dehydrogenase must have been present, because no sulfite was observed during growth (Figs $2 \mathrm{~b}$ and $3 \mathrm{~b}$ ), but no enzyme activity was detected in cell extracts. The acceptors tested for the direct oxidation (Kappler \& Dahl, 2001) were cytochrome $c$ and ferricyanide, so neither the known sulfite dehydrogenase, SorAB (Kappler et al., 2000), nor the cytochrome $c$-independent enzyme (Reichenbecher et al., 1999; Gorzynska et al., 2006; Weinitschke et al., 2006), was detected. The acceptors tested for the AMP-dependent (indirect) pathway of sulfite oxidation (Hagen \& Nelson, 1997; Kappler \& Dahl, 2001) were ferricyanide and cytochrome $c$. The absence of SorAB (and SoxCD) could be anticipated from the genome sequence, and the indirect pathway is oxygen-sensitive (Schiffer et al., 2006), so it is unclear whether the undefined ferricyanide-coupled enzyme (Reichenbecher et al., 1999), or a novel enzyme, catalyses the oxidation of sulfite.

The product of sulfite dehydrogenase is sulfate, which is believed to be exported from the cell by TauZ (Rein et al., 2005). A strong transcript of the tau $Z$ gene was detected in taurine(carbon)-ammonium-grown cells, but not in succinate-ammonium-grown cells (Table 3). An amplicon overlapping the tauZ and pta genes was also obtained when using primer RsPtaR for RT (Fig. 4), so these neighbouring genes were co-transcribed. No amplicon was obtained for a transcript representing tauX to $x s c$ (using primers 


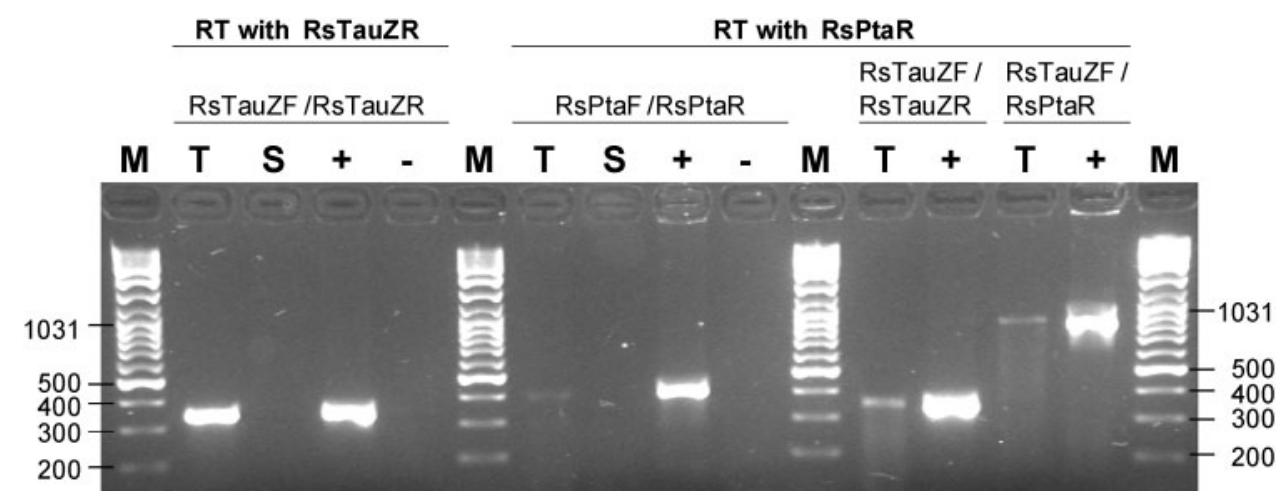

Fig. 4. Transcription and co-transcription of tauZ and pta from $R$. sphaeroides 2.4.1. The predicted sizes of the amplicons with the primer combinations used are: RsTauZF-RsTauZR, 344 bp; RsPtaF-RsPtaR, 410 bp; RsTauZF-RsPtaR, 822 bp. Lanes: M, GeneRuler DNA ladder mix; T, RNA from taurine(carbon)-ammonium-grown cells; S, RNA from succinateammonium-grown cells; +, positive control (genomic DNA); -, negative control $\left(\mathrm{H}_{2} \mathrm{O}\right.$ as template). Relevant marker sizes (in $\mathrm{bp)}$ are indicated on the left-hand and right-hand sides of the figure.

RsTauXF-RsXscR), or of a transcript representing $x s c$ to tauZ (using primers RsXscF-RsTauZR); this suggests separate transcripts for tauXY, for $x s c$ and for tauZ-pta in R. sphaeroides 2.4.1.

No activity of isocitrate lyase was detected in $R$. sphaeroides 2.4.1 (Table 3), as observed and cited by, for example, Filatova et al. (2005) and anticipated from the absence of the corresponding gene in the genome. The apparent activity of malate synthase was detected at a high level in taurine(carbon)-ammonium-grown cells, but at much lower levels in taurine(nitrogen)-succinate grown cells and in succinate-ammonium grown cells (Table 3). Malate synthase is one enzyme in Ivanovsky's anaplerotic pathway (e.g. Filatova et al., 2005), but Meister et al. (2005) have shown this to result from the combined activity of malylCoA lyase (EC 4.1.3.24) and of a putative malyl-CoA hydrolase. We could confirm the presence of malyl-CoA lyase in crude extracts (Table 3 ) and detect a putative malylCoA hydrolase activity in fractions of the extract (not shown), analogous to the data of Meister et al. (2005). Correspondingly, the gene annotated to encode malate synthase, RSP_1980, was not transcribed under the conditions tested (Table 3 ).

Proteins in the extracts of cells grown in succinateammonium medium or in taurine(carbon)-ammonium medium were separated by SDS-PAGE (not shown). One inducible protein only could be observed in extracts of taurine(carbon)-ammonium-grown cells and taurine(nitrogen)-succinate-grown cells. The protein had a molecular mass of about $63 \mathrm{kDa}$, i.e that of Xsc. Soluble extract of taurine(carbon)-ammonium-grown cells was subjected to anion-exchange chromatography and hydrophobic interaction chromatography, and the fraction containing Xsc activity, which was ThDP-dependent, was the essentially pure $63 \mathrm{kDa}$ protein. The activity of Pta was lost rapidly and traces were found in many fractions from the anion exchanger. A single fraction with Pta activity was obtained from soluble extract on the hydrophobic interaction column, but the losses in activity prevented both further chromatography, and useful analyses by SDS-PAGE.

\section{DISCUSSION}

The prediction that $R$. sphaeroides 2.4 .1 would utilize taurine as the sole source of carbon for growth (Brüggemann et al., 2004) has been confirmed, and growth was concomitant with substrate utilization (Fig. 2a, b). Similarly, the idea was confirmed that the organism would utilize taurine as a sole source of nitrogen for growth (Fig. 3a, b). The assimilation of taurine-nitrogen sometimes involves utilization of the compound concomitant with growth, as found in Acinetobacter calcoaceticus SW1, Alcaligenes faecalis MT1 and Rhodococcus opacus ISO-5 (Denger et al., 2004a; Weinitschke et al., 2005, 2006), and sometimes with excretion and subsequent utilization of the ammonium ion as in Rhodopseudomonas palustris CGA009 (Denger et al., 2004b), as shown in Fig. 3(b). When the organism can utilize taurine as sole source of both carbon and nitrogen, the same pathway is obviously involved, via Tpa (and Ald) in $R$. opacus ISO-5 (Denger et al., 2004a) and via TDH in $R$. sphaeroides 2.4.1 (Table 3). We have no explanation for the excretion or non-excretion of the ammonium ion during growth of different organisms with limiting amounts of taurine.

One key, novel aspect of the degradative pathway proposed by Brüggemann et al. (2004) is the TRAP transporter, TauKLM. We now present the first experimental evidence (Table 3) that the genes are transcribed, and presumably translated. The assumption of function is the sequence similarity to TRAP transporters for dicarboxylates (DctPQM) from Rhodobacter capsulatus (e.g. Forward et al., 1997): TauK and DctP share $22 \%$ identity. Gene orthologues of tauKLM have now been found in the 
genomes of several organisms which contain the $x s c$ gene and do, or can be expected to, dissimilate taurine [two other members of the Rhodobacterales (e.g. Brüggemann et al., 2004), Desulfotalea psychrophila LSv54 (R. Rabus, personal communication) and three untested $\gamma$-Proteobacteria (Vibrionales)]. Transport of taurine via a TRAP transporter thus seems to be widespread.

The degradative pathway for taurine via TDH (Brüggemann et al., 2004) was detected (Table 3). There was no direct proof that tauXY was involved in the pathway, but the inducible co-transcription of the two genes supports a role for the gene products, which we consider to be TDH. Heterologous expression of the tauXY genes has not yet been successful (T. H. M. Smits, unpublished), and solublization of the membrane fraction led to loss of enzyme activity (K. Denger, unpublished). The identity of the cytochrome $c$ which accepts electrons from TDH, is also unknown.

The prediction of a role for Tpa in taurine dissimilation by $R$. sphaeroides 2.4.1, from both sequence analysis (see Introduction) and enzyme assays in $R$. sphaeroides Tau3 (Novak et al., 2004), was not confirmed. Some aminotransferase activity could, indeed, be detected, but at lower levels than in succinate-ammonium-grown cells (Table 3). We presume the taurine: pyruvate aminotransferase activity to represent the side reaction of a different aminotransferase. Work with the Tpa from Bilophila wadsworthia RZATAU showed that the sequences of some Tpa orthologues cluster together, whereas others are spread amongst class III aminotransferases of different or unknown functions (Laue et al., 2006). The hypothetical ABC transporter ('NsbABC'; Fig. 1b, Table 3) encoded upstream of this transaminase is a member of a large group of uncharacterized $\mathrm{ABC}$ transporters closely related to $\mathrm{TC}$ 3.A.1.12/16/17.- which are unfortunately termed TauABC, identical to the TauABC transporters involved in taurine metabolism (TC 3.A.1.17.1) (Eichhorn et al., 2000; Gorzynska et al., 2006). TauA and NsbA share $<20 \%$ sequence identity. It is unlikely that 'NsbABC' (Table 3) plays any role in taurine metabolism in R. sphaeroides 2.4.1.

Xsc is the only enzyme in the pathway which has been regularly purified (Denger et al., 2001, 2004a; Ruff et al., 2003; Brüggemann et al., 2004). In the present paper, the enzyme could be purified to near homogeneity in two steps. Indeed, the $x s c$ gene is our marker for the presence of the degradation of a $\mathrm{C}_{2}$-sulfonate in a genome (see Cook \& Denger, 2002), and some 25 organisms have been confirmed to express the enzyme (e.g. Gorzynska et al., 2006), or at least grow with a $\mathrm{C}_{2}$-sulfonate ( $\mathrm{K}$. Denger, unpublished), and the number is steadily increasing.

Pta, in contrast, frequently presents a problem, because the enzyme is labile under our standard conditions (e.g. Weinitschke et al., 2006), a phenomenon which seems to be widespread (Lawrence et al., 2006). In the present study, the enzyme rapidly lost activity and could not be satisfactorily separated by anion-exchange chromatography.
Higher stability was attained for hydrophobic interaction chromatography, but the very low amount of partially purified protein did not allow an estimation of the molecular mass of the enzyme.

There will be several fates for the acetyl-CoA formed by Pta. A minor portion will flow to fatty acid synthesis. A major portion will be oxidized via the Krebs cycle, and a significant portion will flow through an anaplerotic sequence to maintain the supply of oxaloacetate for the Krebs cycle. The nature of this anaplerotic pathway is unclear, because $R$. sphaeroides has been known for some 40 years to lack one key enzyme of the glyoxylate shunt, isocitrate lyase. Ivanovsky's group, working in crude extracts, has postulated a citramalate cycle, which involves malate synthase (e.g. Filatova et al., 2005). Fuchs' group has started to clarify this pathway by purifying enzymes, and a recent article shows that the apparent measurement of malate synthase represents the combined activity of malyl-CoA lyase and a malylCoA hydrolase (Meister et al., 2005). Our data (e.g. Table 3) support this latter observation. Whatever the nature of the complete anaplerotic pathway (see Alber et al., 2006), the apparent malate synthase in crude extract shows the cycle to be present at high levels in the taurine(carbon)-ammoniumgrown cells, but only in traces in taurine(nitrogen)succinate-grown cells (Table 3 ). Presumably, when taurine is supplying nitrogen in the presence of a $\mathrm{C}_{4}$ carbon source in excess (in our case succinate), the anaplerotic sequence is not necessary, and is regulated independently of the operation of the taurine degradative pathway. The gene RSP_1980, annotated as malate synthase $(g l c B)$, is not transcribed under the tested conditions (Table 3 ), so it plays no role in the anaplerotic sequence; an alternative function for an orthologue in Mycobacterium tuberculosis has been demonstrated to be that of an adhesin (Kinhikar et al., 2006).

During the dissimilation of taurine, not only the flow of carbon but also the fluxes of ammonia/ammonium ion and sulfite/sulfate ions must be contained. It seems logical to consider that the single copy of the amtB gene will be involved (e.g. Khademi et al., 2004; Gorzynska et al., 2006), but we obtained no reproducible data. The nature of the oxidation of sulfite to sulfate is also unknown. The sulfate is presumably excreted via the inducible TauZ (Fig. 1a, b, Table 3).

\section{ACKNOWLEDGEMENTS}

We are grateful to M. Schwederski and J. H. Klemme (University of Bonn), who introduced us to Rhodobacter sphaeroides, and to M. Birk, T. Hammer, M. Knuth and B. Kraus for data collected during practical classes for advanced students. R. Rabus (Max Planck Institute for Marine Microbiology, Bremerhaven, Germany) kindly confirmed our hypothesis that Desulfotalea psychrophila LSv54 would grow with taurine as carbon source and electron sink. The sequence data for $R$. sphaeroides 2.4 .1 were generated by the US Department of Energy, Joint Genomic Institute (http://www.jgi.doe.gov), and we gratefully acknowledge the discussions with S. Kaplan (University of Texas, 
Houston, TX, USA) and B. E. Alber (University of Freiburg, Germany) during the course of the work; B. E. Alber generously supplied the malyl-CoA. The project was supported by the University of Konstanz.

\section{REFERENCES}

Abraham, W.-R., Strömpl, C., Vancanneyt, M., Bennasar, A., Swings, J., Lünsdorf, H., Smit, J. \& Moore, E. R. B. (2004). Woodsholea maritima gen. nov., sp. nov., a marine bacterium with a low diversity of polar lipids. Int J Syst Evol Microbiol 54, 1227-1234.

Alber, B. E., Spanheimer, R., Ebenau-Jehle, C. \& Fuchs, G. (2006). Study of an alternative glyoxylate cycle for acetate assimilation by Rhodobacter sphaeroides. Mol Microbiol 61, 297-309.

Allen, J. A. \& Garrett, M. R. (1971). Taurine in marine invertebrates. Adv Mar Biol 9, 205-253.

Altschul, S. F., Madden, T. L., Schäffer, A. A., Zhang, J., Zhang, Z., Miller, W. \& Lipman, D. J. (1997). Gapped BLAST and PSI-BLAST: a new generation of protein database search programs. Nucleic Acids Res 25, 3389-3402.

Bergmeyer, H. U., GraßI, M. \& Walter, E.-M. (1983). Phosphotransacetylase. In Methods of Enzymatic Analysis, pp. 295-296. Edited by H. U. Bergmeyer. Weinheim: Verlag Chemie.

Bradford, M. (1976). A rapid and sensitive method for the quantitation of microgram quantities of protein utilizing the principle of protein-dye binding. Anal Biochem 72, 248-254.

Brüggemann, C., Denger, K., Cook, A. M. \& Ruff, J. (2004). Enzymes and genes of taurine and isethionate dissimilation in Paracoccus denitrificans. Microbiology 150, 805-816.

Cook, A. M. (1987). Biodegradation of $s$-triazine xenobiotics. FEMS Microbiol Rev 46, 93-116.

Cook, A. M. \& Hütter, R. (1981). s-Triazines as nitrogen sources for bacteria. J Agric Food Chem 29, 1135-1143.

Cook, A. M. \& Denger, K. (2002). Dissimilation of the $\mathrm{C}_{2}$ sulfonates. Arch Microbiol 179, 1-6.

Cook, A. M. \& Denger, K. (2006). Metabolism of taurine in microorganisms: a primer in molecular diversity? Adv Exp Med Biol 583, 3-13.

Denger, K., Laue, H. \& Cook, A. M. (1997). Anaerobic taurine oxidation: a novel reaction by a nitrate-reducing Alcaligenes sp. Microbiology 143, 1919-1924.

Denger, K., Ruff, J., Rein, U. \& Cook, A. M. (2001). Sulfoacetaldehyde sulfo-lyase [EC 4.4.1.12] from Desulfonispora thiosulfatigenes: purification, properties and primary sequence. Biochem J 357, 581-586.

Denger, K., Ruff, J., Schleheck, D. \& Cook, A. M. (2004a). Rhodococcus opacus expresses the xsc gene to utilize taurine as a carbon source or as a nitrogen source but not as a sulfur source. Microbiology 150, 1859-1867.

Denger, K., Weinitschke, S., Hollemeyer, K. \& Cook, A. M. (2004b). Sulfoacetate generated by Rhodopseudomonas palustris from taurine. Arch Microbiol 182, 254-258.

Denger, K., Smits, T. H. M. \& Cook, A. M. (2006). L-Cysteate sulfolyase, a widespread, pyridoxal $5^{\prime}$-phosphate-coupled desulfonative enzyme purified from Silicibacter pomeroyi DSS- $3^{\mathrm{T}}$. Biochem J 394, 657-664.

Desomer, J., Crespi, M. \& Van Montagu, M. (1991). Illegitimate integration of non-replicative vectors in the genome of Rhodococcus fascians upon electrotransformation as an insertional mutagenesis system. Mol Microbiol 5, 2115-2124.

Dixon, G. H. \& Kornberg, H. L. (1959). Assay methods for key enzymes of the glyoxylate cycle. Biochem $J$ 72, 3P.
Eichhorn, E., van der Ploeg, J. R. \& Leisinger, T. (2000). Deletion analysis of the Escherichia coli taurine and alkanesulfonate transport systems. J Bacteriol 182, 2687-2795.

Filatova, L. V., Berg, I. A., Krasil'nikova, E. N. \& Ivanovsky, R. N. (2005). A study of the mechanism of acetate assimilation in purple nonsulfur bacteria lacking the glyoxylate shunt: enzymes of the citramalate cycle in Rhodobacter sphaeroides. Microbiology (English translation of Mikrobiologiia) 74, 270-278.

Forward, J. A., Behrendt, M. C., Wyborn, N. R., Cross, R. \& Kelly, D. J. (1997). TRAP transporters: a new family of periplasmic solute transport systems encoded by the dctPQM genes of Rhodobacter capsulatus and by homologs in diverse gram-negative bacteria. J Bacteriol 179, 5482-5493.

Gesellschaft Deutscher Chemiker (1996). German Standard Methods for the Laboratory Examination of Water, Waste Water and Sludge. Weinheim: Verlag Chemie.

Gorzynska, A. K., Denger, K., Cook, A. M. \& Smits, T. H. M. (2006). Inducible transcription of genes involved in taurine uptake and dissimilation by Silicibacter pomeroyi DSS $-3^{\mathrm{T}}$. Arch Microbiol 185, 402-606.

Hagen, K. D. \& Nelson, D. C. (1997). Use of reduced sulfur compounds by Beggiatoa spp.: enzymology and physiology of marine and freshwater strains in homogeneous and gradient cultures. Appl Environ Microbiol 63, 3957-3964.

Huxtable, R. J. (1992). Physiological actions of taurine. Physiol Rev 72, 101-163.

Innis, M. A., Gelfand, D. H., Sninsky, J. J. \& White, T. J. (1990). PCR Protocols. A Guide to Methods and Applications. San Diego: Academic Press.

Kappler, U. \& Dahl, C. (2001). Enzymology and molecular biology of prokaryotic sulfite oxidation. FEMS Microbiol Lett 203, 1-9.

Kappler, U., Bennett, B., Rethmeier, J., Schwarz, G., Deutzmann, R., McEwan, A. G. \& Dahl, C. (2000). Sulfite:cytochrome $c$ oxidoreductase from Thiobacillus novellus. Purification, characterization, and molecular biology of a heterodimeric member of the sulfite oxidase family. J Biol Chem 275, 13202-13212.

Kertesz, M. A. (2000). Riding the sulfur cycle - metabolism of sulfonates and sulfate esters in Gram-negative bacteria. FEMS Microbiol Rev 24, 135-175.

Khademi, S., O'Connell, J., III, Remis, J., Robles-Colmenares, Y., Miercke, L. J. \& Stroud, R. M. (2004). Mechanism of ammonia transport by Amt/MEP/Rh: structure of AmtB at 1.35 A. Science 305, 1587-1594.

Kinhikar, A. G., Vargas, D., Li, H., Mahaffey, S. B., Hinds, L., Belisle, J. T. \& Laal, S. (2006). Mycobacterium tuberculosis malate synthase is a laminin-binding adhesin. Mol Microbiol 60, 999-1013.

Laemmli, U. K. (1970). Cleavage of structural proteins during the assembly of the head of bacteriophage T4. Nature 227, 680-685.

Laue, H. \& Cook, A. M. (2000a). Purification, properties and primary structure of alanine dehydrogenase involved in taurine metabolism in the anaerobe Bilophila wadsworthia. Arch Microbiol 174, 162-167.

Laue, H. \& Cook, A. M. (2000b). Biochemical and molecular characterization of taurine:pyruvate aminotransferase from the anaerobe Bilophila wadsworthia. Eur J Biochem 267, 6841-6848.

Laue, H., Smits, T. H. M., Schumacher, U., Claros, M., Hartemink, R. \& Cook, A. M. (2006). Identification of Bilophila wadsworthia in enrichment cultures by specific PCR which targets the taurine:pyruvate aminotransferase gene. FEMS Microbiol Lett 261, 74-79.

Lawrence, S. H., Luther, K. B., Schindelin, H. \& Ferry, J. G. (2006). Structural and functional studies suggest a catalytic mechanism for the phosphotransacetylase from Methanosarcina thermophila. $J$ Bacteriol 188, 1143-1154. 
Lie, T. L., Leadbetter, J. R. \& Leadbetter, E. R. (1998). Metabolism of sulfonic acids and other organosulfur compounds by sulfatereducing bacteria. Geomicrobiol J 15, 135-149.

Masepohl, B., Führer, F. \& Klipp, W. (2001). Genetic analysis of a Rhodobacter capsulatus gene region involved in utilization of taurine as a sulfur source. FEMS Microbiol Lett 205, 105-111.

Mayer, J., Denger, K., Smits, T. H. M., Hollemeyer, K., Groth, U. \& Cook, A. M. (2006). N-Acetyltaurine dissimilated via taurine by Delftia acidovorans NAT. Arch Microbiol 186, 61-67.

Meister, M., Saum, S., Alber, B. E. \& Fuchs, G. (2005). L-Malylcoenzyme $\mathrm{A} / \beta$-methylmalyl-coenzyme A lyase is involved in acetate assimilation of the isocitrate lyase-negative bacterium Rhodobacter capsulatus. J Bacteriol 187, 1415-1425.

Novak, R. T., Gritzer, R. F., Leadbetter, E. R. \& Godchaux, W. (2004). Phototrophic utilization of taurine by the purple nonsulfur bacteria Rhodopseudomonas palustris and Rhodobacter sphaeroides. Microbiology 150, 1881-1891.

Reichenbecher, W., Kelly, D. P. \& Murrell, J. C. (1999). Desulfonation of propanesulfonic acid by Comamonas acidovorans strain P53: evidence for an alkanesulfonate sulfonatase and an atypical sulfite dehydrogenase. Arch Microbiol 172, 387-392.

Rein, U., Gueta, R., Denger, K., Ruff, J., Hollemeyer, K. \& Cook, A. M. (2005). Dissimilation of cysteate via 3-sulfolactate sulfo-lyase and a sulfate exporter in Paracoccus pantotrophus NKNCYSA. Microbiology 151, 737-747.

Ruff, J., Denger, K. \& Cook, A. M. (2003). Sulphoacetaldehyde acetyltransferase yields acetyl phosphate: purification from Alcaligenes defragrans and gene clusters in taurine degradation. Biochem J 369, 275-285.

Sambrook, J., Fritsch, E. F. \& Maniatis, T. (1989). Molecular Cloning: a Laboratory Manual, 2nd edn. Cold Spring Harbor: Cold Spring Harbor Laboratory.
Schiffer, A., Fritz, G., Kroneck, P. M. \& Ermler, U. (2006). Reaction mechanism of the iron-sulfur flavoenzyme adenosine-5' ${ }^{\prime}$-phosphosulfate reductase based on the structural characterization of different enzymatic states. Biochemistry 45, 2960-2967.

Sistrom, W. R. (1962). The kinetics of the synthesis of photopigments in Rhodopseudomonas sphaeroides. J Gen Microbiol 28, 607-616.

Sörbo, B. (1987). Sulfate: turbidimetric and nephelometric methods. Methods Enzymol 143, 3-6.

Styp von Rekowski, K., Denger, K. \& Cook, A. M. (2005). Isethionate as a product from taurine during nitrogen-limited growth of Klebsiella oxytoca Tau-N1. Arch Microbiol 183, 325-330.

Thurnheer, T., Köhler, T., Cook, A. M. \& Leisinger, T. (1986). Orthanilic acid and analogues as carbon sources for bacteria: growth physiology and enzymic desulphonation. J Gen Microbiol 132, 1215-1220.

Vollrath, F., Fairbrother, W. J., Williams, R. J. P., Tillinghast, E. K., Bernstein, D. T., Gallagher, K. S. \& Townley, M. A. (1990). Compounds in the droplets of the orb spider's viscid spiral. Nature 345, 526-528.

Weinitschke, S., Styp von Rekowski, K., Denger, K. \& Cook, A. M. (2005). Sulfoacetaldehyde is excreted quantitatively by Acinetobacter calcoaceticus SW1 during growth with taurine as sole source of nitrogen. Microbiology 151, 1285-1290.

Weinitschke, S., Denger, K., Smits, T. H. M., Hollemeyer, K. \& Cook, A. M. (2006). The sulfonated osmolyte $N$-methyltaurine is dissimilated by Alcaligenes faecalis and by Paracoccus versutus with release of methylamine. Microbiology 152, 1179-1186.

Weisburg, W. G., Barns, S. M., Pelletier, D. A. \& Lane, D. J. (1991). $16 \mathrm{~S}$ ribosomal DNA amplification for phylogenetic study. J Bacteriol 173, 697-703.

Yin, M., Palmer, H. R., Fyfe-Johnson, A. L., Bedford, J. J., Smith, R. A. \& Yancey, P.H.(2000). Hypotaurine, $N$-methyltaurine, taurine, and glycine betaine as dominant osmolytes of vestimentiferan tubeworms from hydrothermal vents and cold seeps. Physiol Biochem Zool 73, 629-637. 